\title{
The role of SARC-F scale in predicting progression risk of COVID-19 in elderly patients: a prospective cohort study in Wuhan
}

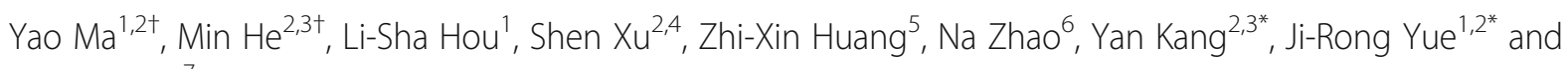
Chenkai $\mathrm{Wu}^{7}$

\begin{abstract}
Background: Since the outbreak of COVID-19, it has been documented that old age and underlying illnesses are associated with poor prognosis among COVID-19 patients. However, it is unknown whether sarcopenia, a common geriatric syndrome, is associated with poor prognosis among older COVID-19 patients. The aim of our prospective cohort study is to investigate the association between sarcopenia risk and severe disease among COVID-19 patients aged $\geq 60$ years.
\end{abstract}

Method: A prospective cohort study of 114 hospitalized older patients ( $\geq 60$ years) with confirmed COVID-19 pneumonia between 7 February, 2020 and 6 April, 2020. Epidemiological, socio-demographic, clinical and laboratory data on admission and outcome data were extracted from electronic medical records. All patients were assessed for sarcopenia on admission using the SARC-F scale and the outcome was the development of the severe disease within 60 days. We used the Cox proportional hazards model to identify the association between sarcopenia and progression of disease defined as severe cases in a total of 2908 person-days.

Result: Of 114 patients (mean age $69.52 \pm 7.25$ years, 50\% woman), 38 (33\%) had a high risk of sarcopenia while 76 (67\%) did not. We found that 43 (38\%) patients progressed to severe cases. COVID-19 patients with higher risk sarcopenia were more likely to develop severe disease than those without (68\% versus $22 \%, p<0.001)$. After adjustment for demographic and clinical factors, higher risk sarcopenia was associated with a higher hazard of severe condition [hazard ratio $=2.87(95 \% \mathrm{Cl}, 1.33-6.16)$ ].

Conclusion: We found that COVID-19 patients with higher sarcopenia risk were more likely to develop severe condition. A clinician-friendly assessment of sarcopenia could help in early warning of older patients at high-risk with severe COVID-19 pneumonia.

Keywords: COVID-19, SARC-F, Sarcopenia, Prognosis, Older

\footnotetext{
*Correspondence: kangyan@scu.edu.cn; yuejirong11@hotmail.com

${ }^{\dagger}$ Yao $\mathrm{Ma}$ and Min He contributed equally to this work.

${ }^{2}$ COVID-19 Medical Assistance Teams (Hubei) of West China Hospital, Sichuan University, Chengdu, Sichuan Province, China

'Department of Geriatrics and National Clinical Research Center for Geriatrics, West China Hospital, Sichuan University, Chengdu, Sichuan Province, China

Full list of author information is available at the end of the article
} 


\section{Background}

The coronavirus disease 2019 (COVID-19) is an acute respiratory infectious disease caused by infection with SARS-CoV-2 (Severe acute respiratory syndrome coronavirus 2). COVID-19 is highly contagious and could lead to a high rate of severe illness $[1,2]$. Since the outbreak in December 2019, COVID-19 has swept the world and more than two hundred countries and regions have been affected. As of 13 April, 2021, there have been $136,115,434$ confirmed cases of COVID-19, including 2, 936,916 deaths [3].

About 15\% of COVID-19 cases experienced severe disease (covid-strategy-update-14april2020.pdf) and the fatality rate ranged from 1.4 to $14 \%$ among hospitalized patients [4-6]. Studies have shown that COVID-19 patients with older age, comorbidities, lactic dehydrogenase (LHD) and D-dimer, are at more likely to develop severe complications and die [7-9]. Older adults are more vulnerable to be infected and at higher risk of developing serious complications with COVID-19. The mortality rate for older people could be incredibly high and meanwhile the fatality rate of those over 80 years old is five times the global average (covid-strategyupdate-14april2020.pdf). The COVID-19 pandemic has posed a disproportionately high threat to older adults [10-12]. Older adults represent a diverse population with hugely different health status; chronological age alone may not capture the full risk spectrum and may not truly reflect the differences underlying the biological ageing process. Therefore, it is scientifically unreasonable to give up treatment based on chorological age alone.

The concept of sarcopenia was originally proposed by Rosenberg in 1989. Sarcopenia is characterized by a progressive decline in skeletal muscle mass, power and strength, whereas frailty still requires the loss of performance $[13,14]$. The prevalence of sarcopenia is about 5 to $70 \%$, depending on age, sex and different diagnostic criteria [15-18]. Sarcopenia is strongly associated with falls, fractures, disability, and high healthcare expenditures [19]. Studies have shown that frailty was a better predictor for prognosis of COVID-19 than either age or comorbidity $[20,21]$. Sarcopenia shares the similar pathogenesis with frailty and is often considered as a precursor to frailty $[22,23]$. We assume that age-related sarcopenia is a risk factor for the aggravation of the patient's condition. Early identification of patients with a high risk of sarcopenia can help us advance the timing of intervention to avoid the deterioration of the patient's condition to an extremely serious state and a state requiring a lot of resources. We conducted a prospective cohort study to investigate the association between sarcopenia, and progression risk among older COVID-19 patients. Sarcopenia was assessed the SARC-F scale which is an inexpensive and clinic-friendly screening tool with satisfactory reliability and specificity [24].

\section{Methods \\ Study design and participants}

This is a prospective cohort study conducted in East Campus of Renmin Hospital of Wuhan University/Hubei General Hospital by COVID-19 medical team (Hubei) of West-China hospital. This study was performed according to the Helsinki Declaration and approved by the Ethics Committee of West China Hospital. Because no paper documents are allowed to be taken out of the quarantine area, the requirement for written informed consent was waived by the Ethics Committee of West China Hospital and informed consent was obtained verbally (Y.M) from all participants.

A total of 114 patients over 60 years old newly diagnosed with COVID-19 from February 7 to April 6, 2020 were enrolled in this study. The inclusion criteria were: (1) age $\geq 60$ years; (2) diagnosis of COVID-19 pneumonia confirmed by positive result for COVID-19 RNA in nasopharyngeal swabs according to the WHO interim guidance published on 28 January, 2020 [25]; (3) completion of SARC-F assessment on admission; (4) availability of relevant medical record information. Patients with the following conditions will be excluded: incomplete information; don't comply with treatment; don't comply with questionnaire survey; Mental disorders and consciousness disorder; be critically ill when admitted.

\section{Data and specimen collection Sarcopenia risk}

We evaluated patients through face-to-face interviews and completed the SARC-F scale by experienced geriatricians within $24 \mathrm{~h}$ of admission. We used the SARC-F scale to measure risk of sarcopenia. Five components were included: strength; assistance walking; rise from a chair; climb stairs; and falls. Each type of evaluation item contains 0 points, 1 point, and 2 points according to the degree of difficulty or frequency. The total score ranges from 0 to 10 . Patients with a total score $\geq 4$ were considered to have a high risk of sarcopenia [24].

\section{Socio-demographics and clinical conditions}

Patients' demographics (age and sex), health behaviors (smoking and body mass index [BMI]), medical history, comorbidities (hypertension, diabetes, coronary heart disease, stroke, cancer, chronic pulmonary disease, and chronic kidney disease), vital sign on admission, clinical conditions (fever, fatigue, myalgia, pharyngalgia, dry cough, expectoration, hemoptysis, dyspnea, chest pain, anorexia, diarrhea, nausea) and laboratory data (white blood cell count, lymphocyte count, haemoglobin, albumin, creatinine, $\mathrm{CD} 8+$, D-dimer, C-reactive protein 
[CRP]) were assessed within $24 \mathrm{~h}$ of admission at baseline. Subsequently, changes in the condition (improvement or progression of disease) were evaluated until hospitalization day 60 or death/discharge.

\section{Laboratory data}

Blood samples were taken within $24 \mathrm{~h}$ of hospital admission . Laboratory data (white blood cell count, neutrophil count, lymphocyte count, hemoglobin, albumin, creatinine, CD8+, D-dimer, and C-reactive protein [CRP]) on admission were assessed. We managed the patients in accordance with WHO's guideline and official guideline of China, and closely monitored patients' condition changes $[26,27]$.

\section{Outcomes}

The outcome in our study was development of severe disease within 60 days of hospital admission, defined as fever or suspected respiratory infection plus one of the following conditions according to the WHO Interim guidance for COVID-19: respiratory rate $>30$ breaths/ min; severe respiratory stress; or $\mathrm{SpO} 2 \leq 93 \%$ on room air, as well as acute respiratory distress syndrome (ARDS) which is diagnosed according to the Berlin criteria [27, 28]. Individuals were censored when they were discharged or the end of the analytic period (60 days), whichever came first. Follow-up information was available through April 6, 2020.

\section{Statistical analysis}

We used SAS 9.4 (SAS Institute Inc., Cary, NC, USA) to perform data analysis. We evaluated the normality of the distribution of variables using the Kolmogorov-Smirnov test. Normally distributed data were expressed as mean \pm SD while non-normally distributed data were expressed as median (interquartile range). The difference between patients with and without sarcopenia was tested by independent Student's t-test for normally distributed variables and Mann-Whitney $U$ test for non-normally distributed variables. The chi-square test or Fisher exact test was used to compare categorical variables between patients with and without sarcopenia.

We first calculated the incidence rate of severe disease among the overall sample and by sarcopenia status. We then used the Kaplan-Meier method to plot survival curves. Differences were examined using the log-rank test. We used the Cox proportional hazards models to identify the unadjusted and adjusted associations between sarcopenia and severe disease. All tests were twosided and $P$ values of $\leq 0.05$ were considered as being statistically significant.

\section{Results}

Baseline characteristics

In this prospective cohort study, a total of 114 patients were included (Table 1). The mean age was $69.52 \pm 7.25$ years, and $57(50 \%)$ were women. The average age among patients with low risk of sarcopenia was $68.93 \pm$ 7.00 years and was $72.05 \pm 8.36$ years among patients with a high risk of sarcopenia $(p=0.038)$. There were no statistically significant differences in comorbidities between two groups. There were proportionally more individuals feeling fatigue ( $74 \%$ versus $50.00 \%, p=0.019$ ), dyspnea ( $58 \%$ versus $32 \%, p=0.007)$ and anorexia $(74 \%$ versus $54 \%, p=0.042)$ in patients with a high risk of sarcopenia than those with lower risk. Patients with a high risk of sarcopenia have statistically significantly higher level in white blood cell, neutrophil, hemoglobin, Ddimer, and procalcitonin than those with lower risk. The lymphocyte count, CD3+, CD4+, and CD8+ were statistically significantly lower among patients with a high risk sarcopenia than those with lower risk.

\section{Primary outcome: differences between high risk and low risk of sarcopenia}

Forty-three of 114 (38\%) patients progressed to severe disease including eight deaths during the follow-up period, and the overall incidence rate of severe disease was 1.48 per 100 person-days (95\% confidence interval [CI]: 1.10-1.99; Table 2). We found 22\% (17/76) patients with low risk and $68 \%(26 / 38)$ patients with high risk became severe. The incidence rate of severe disease among patients with high and low risk of sarcopenia was 0.77 per 100 person-days (95\% CI: $0.48-1.24$ ) and 4.41 per 100 person-days (95\% CI: 3.01-6.48), respectively.

We presented the survival curves of two group regarding the severe disease in Fig. 1. There was significant difference between high and low risk of sarcopenia group (Log Rank test, $p<0.001$ ).

In the Cox proportional hazards model, the unadjusted hazard ratio of severe disease was 5.27 (95\%CI, 2.839.82) for patients with a high risk of sarcopenia than those without (Table 3). The association persisted after adjusting for age, fatigue, dyspnea, anorexia, hemoglobin, neutrophil, lymphocyte, D-dimer, procalcitonin, BNP (Brain Natriuretic Peptide) and T cell subsets (CD3+, $\mathrm{CD} 4+, \mathrm{CD} 8+)$. The hazard of having severe disease among patients with a high risk of sarcopenia was almost as 3-fold as those without (hazard ratio $=2.87,95 \%$ CI: $1.33,6.16)$.

\section{Discussion}

In the present study, we focused on a cohort of 114 senior patients (age $\geq 60$ ) tested positive for COVID-19 in order to examine the association between a high risk of sarcopenia and progression to severe case among older 
Table 1 Demographic, clinical, laboratory findings of patients on admission

\begin{tabular}{|c|c|c|c|c|}
\hline Characteristics & Total $(n=114)$ & Low risk of Sarcopenia $(n=76)$ & High risk of sarcopenia $(n=38)$ & $p$ value \\
\hline Age, Years & $69.52 \pm 7.25$ & $68.93 \pm 7.00$ & $72.05 \pm 8.36$ & 0.038 \\
\hline \multicolumn{5}{|l|}{ Sex } \\
\hline Female & $57(50.00 \%)$ & $38(50.00 \%)$ & $19(50.00 \%)$ & \multirow[t]{2}{*}{1.000} \\
\hline Male & $57(50.00 \%)$ & $38(50.00 \%)$ & $19(50.00 \%)$ & \\
\hline Body Mass Index & $23.46 \pm 3.18$ & $23.57 \pm 3.23$ & $23.20 \pm 3.08$ & 0.576 \\
\hline Smoking & $19(16.67 \%)$ & $12(15.79 \%)$ & $7(18.42 \%)$ & 0.722 \\
\hline \multicolumn{5}{|l|}{ Comorbidity } \\
\hline Hypertension & $57(50.00 \%)$ & $37(48.68 \%)$ & $20(52.63 \%)$ & 0.691 \\
\hline Diabetes & $20(17.54 \%)$ & $14(18.42 \%)$ & $6(15.79 \%)$ & 0.728 \\
\hline Coronary heart disease & $10(8.77 \%)$ & $4(5.26 \%)$ & $6(15.79 \%)$ & 0.061 \\
\hline Stroke & $6(5.26 \%)$ & $2(2.63 \%)$ & $4(10.53 \%)$ & 0.075 \\
\hline Cancer & $9(7.89 \%)$ & $7(9.21 \%)$ & $2(5.26 \%)$ & 0.461 \\
\hline Chronic pulmonary disease & $14(12.28 \%)$ & $8(10.52 \%)$ & $6(15.79 \%)$ & 0.420 \\
\hline Chronic kidney disease & $7(6.14 \%)$ & $4(5.26 \%)$ & $3(7.89 \%)$ & 0.581 \\
\hline \multicolumn{5}{|l|}{ Symptoms } \\
\hline Fever & $87(76.32 \%)$ & $60(78.95 \%)$ & $27(71.05 \%)$ & 0.350 \\
\hline Fatigue & $66(52.63 \%)$ & $38(50.00 \%)$ & $28(73.68 \%)$ & 0.019 \\
\hline Myalgia & $10(8.77 \%)$ & $6(7.89 \%)$ & $4(10.53 \%)$ & 0.640 \\
\hline Pharyngalgia & $4(3.51 \%)$ & $3(3.95 \%)$ & $1(2.63 \%)$ & 0.710 \\
\hline Dry cough & $72(63.16 \%)$ & $47(61.84 \%)$ & $25(65.79 \%)$ & 0.680 \\
\hline Expectoration & $37(32.46 \%)$ & $24(31.58 \%)$ & $13(34.21 \%)$ & 0.777 \\
\hline Hemoptysis & $5(4.39 \%)$ & $4(5.26 \%)$ & $1(2.63 \%)$ & 0.518 \\
\hline Dyspnea & $46(40.35 \%)$ & $24(31.58 \%)$ & $22(57.89 \%)$ & 0.007 \\
\hline Chest pain & $4(3.51 \%)$ & $2(2.63 \%)$ & $2(5.26 \%)$ & 0.472 \\
\hline Anorexia & $69(60.53 \%)$ & $41(53.95 \%)$ & $28(73.68 \%)$ & 0.042 \\
\hline Diarrhea & $12(10.53 \%)$ & $9(11.84 \%)$ & $3(7.89 \%)$ & 0.517 \\
\hline Nausea & $11(9.65 \%)$ & $6(7.89 \%)$ & $5(13.16 \%)$ & 0.370 \\
\hline \multicolumn{5}{|l|}{ Laboratory findings } \\
\hline White blood cell count $\left(\times 10^{9} / L\right)$ & $6.50(5.28-8.52)$ & $6.48(5.34-8.51)$ & $6.85(4.89-9.72)$ & 0.016 \\
\hline Neutrophil count $\left(\times 10^{9} / \mathrm{L}\right)$ & $4.19(3.01-5.91)$ & $4.78(3.40-5.95)$ & $5.14(3.46-8.59)$ & 0.002 \\
\hline Lymphocyte count $\left(\times 10^{9} / L\right)$ & $0.82(0.58-1.13)$ & $0.90(0.66-1.35)$ & $0.69(0.52-1.12)$ & 0.002 \\
\hline Platelet $\left(\times 10^{9} / L\right)$ & $204.00(161.00-265.00)$ & $199.00(171.00-261.00)$ & $215.50(152.00-270.50)$ & 0.766 \\
\hline Hemoglobin, g/L & $120.00 \pm 20.91$ & $116.87 \pm 21.06$ & $126.50 \pm 18.46$ & 0.018 \\
\hline Albumin, g/L & $34.90(32.10-37.45)$ & $34.10(32.20-36.50)$ & $36.85(32.30-38.25)$ & 0.147 \\
\hline Creatinine, $\mu \mathrm{mol} / \mathrm{L}$ & 65.00(53.00-79.00) & $61.00(53.00-82.00)$ & $65.00(49.00-73.00)$ & 0.274 \\
\hline D-Dimer, mg/L & $1.55(0.69-4.65)$ & $1.07(0.56-2.47)$ & $2.23(1.17-7.80)$ & 0.013 \\
\hline C-reactive protein, mg/L & $59.10(21.30-110.20)$ & $61.30(21.30-110.70)$ & 53.05(21.75-99.00) & 0.651 \\
\hline Procalcitonin, ng/mL & $0.09(0.06-0.21)$ & $0.07(0.05-0.22)$ & $0.10(0.06-0.18)$ & 0.003 \\
\hline BNP, pg/mL & $270.50(135.00-661.00)$ & $266.80(122.70-457.50)$ & $348.40(159.50-813.70)$ & 0.027 \\
\hline$C D+3$, count $/ \mu l$ & $518.00(317.00-804.00)$ & $538.00(345.00-850.00)$ & $432.00(235.00-707.00)$ & 0.007 \\
\hline$C D+4$, count $/ \mu l$ & $348.00(212.00-513.00)$ & $378.00(230.00-559.00)$ & $277.00(150.50-476.50)$ & 0.006 \\
\hline $\mathrm{CD}+8$, count $/ \mu \mathrm{l}$ & $167.00(81.00-279.00)$ & 193.00(94.00-258.00) & $122.50(76.00-285.00)$ & 0.013 \\
\hline
\end{tabular}

Data are median (IQR), $\mathrm{n}(\%) . p$ values were calculated by Mann-Whitney $\mathrm{U}$ test, $\mathrm{X}^{2}$ test, or Fisher's exact test, as appropriate Abbreviations: BNP Brain Natriuretic Peptide 
Table 2 Overall incidence rate of severe illness and incidence rate by Sarcopenia risk

\begin{tabular}{llll}
\hline Sarcopenia risk & Number of severe diseases & Total person-days & $\begin{array}{l}\text { events per } \mathbf{1 0 0} \\
\text { person-days (95\% Cl) }\end{array}$ \\
\hline Total $(n=114)$ & 43 & 2908 & $1.48(1.10-1.99)$ \\
Low risk $(n=76)$ & 17 & 2198 & $0.77(0.48-1.24)$ \\
High risk $(n=38)$ & 26 & 589 & $4.41(3.01-6.48)$ \\
\hline
\end{tabular}

COVID-19 patients. The study showed that higher risk of sarcopenia, assessed by a simple screening tool, was an independent risk factor of the progression to severe diseases among older COVID-19 patients. These results suggested that a quick and inexpensive test for sarcopenia risk could help timely identify high-risk patients, which in turn accelerate the timeline for necessary treatments.

Results from our study showed that COVID-19 patients with a high risk of sarcopenia had higher frequency of dyspnea, and this might be related to the decreased muscle strength in the respiratory system caused by sarcopenia. Previous studies made meaningful findings regarding the association between sarcopenia and respiratory diseases or complications. A study showed that patients who were entered into the Intensive Care Unit (ICU) due to the need for mechanical ventilation had a more positive correlation between respiratory insufficiency and sarcopenia [29]. Another study found that sarcopenia and pneumonia were closely related, which supports our conclusion [30]. Moreover, a study from Peru showed a higher incidence rate of community-acquired pneumonia among subjects diagnosed with sarcopenia [31].

After adjusting for the potential effects of dyspnea, a high risk of sarcopenia was still significantly associated with the progression of patients' conditions. One possible explanation for this is that patients' worsened conditions may be due to the presence of sarcopenia, which leads to a decline in the compensatory function of respiratory muscles in these patients when suffering from COVID-19, causing the clinical manifestations of decompensation to appear earlier and more acute. Evidence from a previous study can support this conjecture [32]. Said cohort study was conducted to investigate the association between muscle mass and outcome of pneumonia patients. The results showed that lower skeletal muscle mass was associated with higher 90-day mortality rate among patients with pneumonia. Some other studies concluded that protein intake and physical excise could maintain or improve muscle mass and function, which were believed to accelerate recovery and improve prognosis of older patients [33-35].

Above all, although there are many studies showing that age is closely related to the prognosis of patients with COVID-19 [36, 37], after adjusting for age, a high risk of sarcopenia is still an independent risk factor for the older in this study. And this result is consistent with our research hypothesis, that is, it is not age itself, but sarcopenia which contributed to the aggravation of patients' COVID-19 condition. To investigate the mechanism of this phenomenon, studies have also shown that in

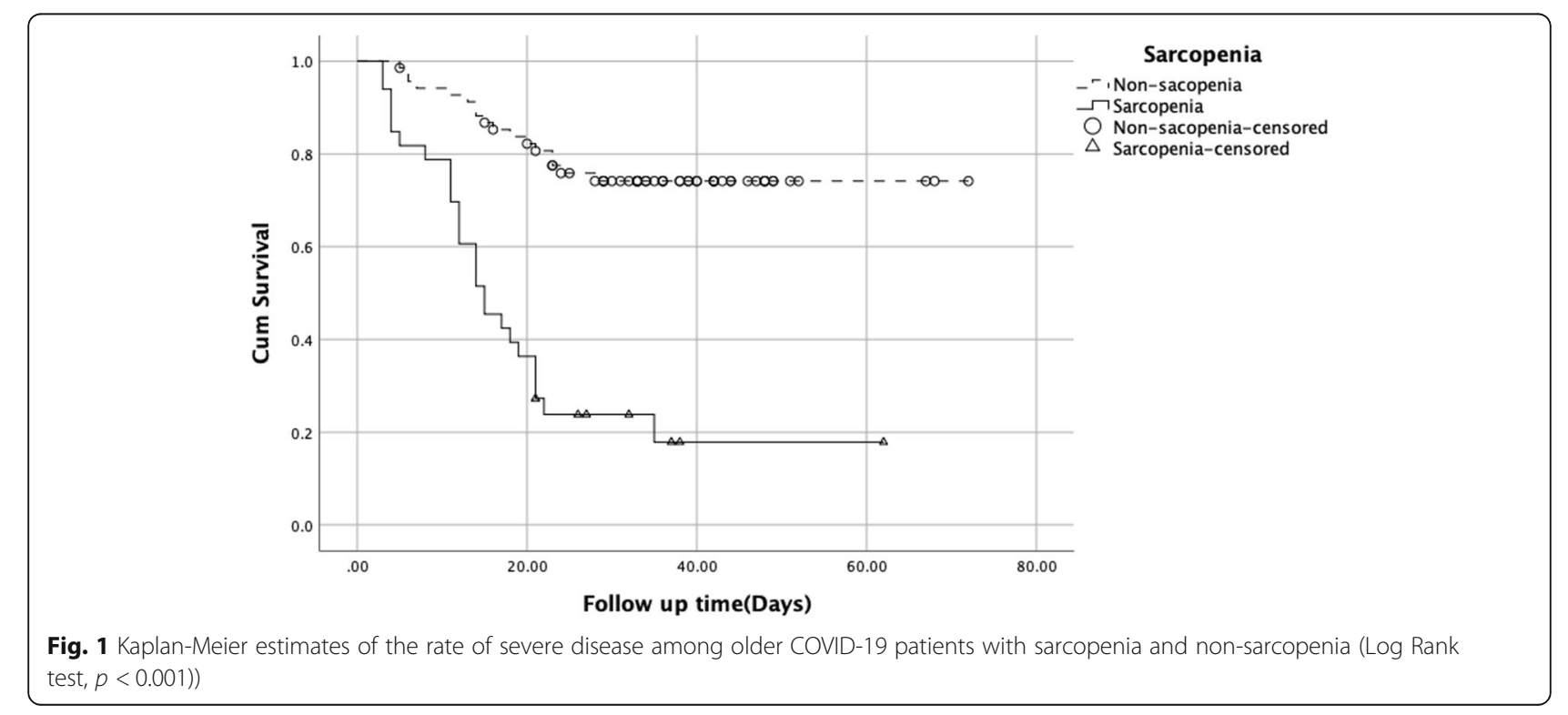


Table 3 Association between sarcopenia risk and severe disease

\begin{tabular}{lll}
\hline & Unadjusted model & Adjusted model \\
\hline Sarcopenia risk & Hazard ratio (95\% confidence interval) \\
Low risk & Ref. & Ref. \\
High risk & $5.268(2.828-9.816)$ & $2.867(1.334-6.161)$
\end{tabular}

Adjusting for age, fatigue, dyspnea, anorexia, hemoglobin, neutrophil, lymphocyte, D-dimer, procalcitonin, BNP and T cell subsets (CD3+, $\mathrm{CD} 4+, \mathrm{CD} 8+)$

Abbreviations: BNP Brain Natriuretic Peptide

addition to the decline in respiratory muscle function, inflammation and immune dysfunction are also closely related to sarcopenia [38-40].

Recent studies suggested that inflammatory storm is an important factor in the progression of COVID-19 patients' prognosis $[41,42]$. The presence of chronic inflammation can accelerate muscle loss and degradation, while muscle recovery can reduce the impact of chronic inflammation on the body to a certain extent [43]. IL-6, which is related to the pathogenesis of sarcopenia [44], plays an important role in the inflammatory storm of COVID-19 [45, 46]. In addition to activating immune system function against pathogens, IL-6 signaling is also a part of age-related chronic inflammation [47] and is related to the pathogenesis of sarcopenia [40]. Chronic low-grade inflammation is associated with prolonged exposure to IL-6 signaling [48], which may contribute to the progression of COVID-19 in older patients $[49,50]$. In addition, the dynamic balance of skeletal muscle could contribute to the maintenance of healthy immune function [47].

Lastly, this study still has room for improvement which can be achieved through addressing several limitations. First of all, this study was conducted in a single isolated hospital with limited sample size. A multi-site large-scale cohort study of COVID-19 patients from all over the world will help further investigate the association between sarcopenia and COVID-19 prognosis. Secondly, this study measured sarcopenia risk by the SARC-F scale due to restrictions brought on by the epidemic-preventive conditions. Although SARC-F is a screening tool for sarcopenia, not a diagnostic instrument, partly due to its debatable sensitivity, it has well repeatability and high specificity with good screening effect. In addition, as a brief scale, it can be easily performed in a busy clinic setting and could minimize the exposure risk to COVID-19 infection among healthcare providers [51-53]. Future studies should adopt more accurate muscle quantification tests and a combination of multiple diagnostic methods to assess sarcopenia. Finally, our observation time was too short to observe the patient's final outcome and long-term prognosis.

\section{Conclusion}

This study found that patients with a higher risk of sarcopenia have a greater risk of developing severe COVID19 symptoms, and that using a simple and feasible scale can help us timely identify high-risk patients. We should never give up older patients prematurely during a pandemic. Instead, we need to find the cause of their exacerbation or even death, intervene in advance, and save lives.

\section{Abbreviations}

COVID-19: Coronavirus disease 2019; ICU: Intensive care unit; WHO: World health organization; CRP: C-reactive protein; CD4+: Cluster of differentiation 4; CD8+: Cluster of differentiation 8

\section{Acknowledgements}

We acknowledge all healthcare workers involved in the diagnosis and treatment of patients in Renmin Hospital of Wuhan University and COVID-19 Medical Team (Hubei) of West China Hospital, Sichuan University.

\section{Authors' contributions}

Dr. Ji-Rong Yue and Dr. Yan Kang had full access to all the data in the study and takes responsibility for the integrity of the data and the accuracy of the data analysis. Study concept and desi gn: Yao Ma, Min He, Ji-Rong Yue, Yan Kang. Acquisition, analysis, or interpretation of data: Yao Ma, Shen Xu, Na Zhao, Zhi-xin Huang, Ji-Rong Yue, Yan Kang, Chenkai Wu. Drafting of the manuscript: Min He. Critical revision of the manuscript for important intellectual content: Yao Ma, Ji-Rong Yue; Chenkai Wu. Statistical analysis: Li-Sha Hou, Min He, Shen Xu Obtained funding: Ji-Rong Yue, Yan Kang. Administrative, technical, or material support: Ji-Rong Yue, Yan Kang, Chenkai Wu. Study supervision: Ji-Rong Yue. The authors read and approved the final manuscript.

\section{Funding}

This study was supported by grants from Chinese National Science \& Technology Pillar Program (2020YFC2005600), Sichuan Science and Technology Program (2020YFS0148), 1.3.5 project for disciplines of excellence-Clinical Research Incubation Project, West China Hospital, Sichuan University(19HXFH012), National Clinical Research Center for Geriatrics, West China Hospital, Sichuan University (Z20191003), Project of Novel Coronavirus Pneumonia in West China Hospital (HX2019nCoV027).

\section{Availability of data and materials}

The datasets used and/or analyzed during the current study are available from the corresponding author on reasonable request. Dr. Jirong Yue and Dr. Yan Kang had full access to all the data in the study and take responsibility for the integrity of the data and the accuracy of the data analysis.

\section{Declarations}

Ethics approval and consent to participate

This study was performed according to the Helsinki Declaration and approved by the Ethics Committee of West China Hospital (West China Hospital \#2020198). Because no paper documents are allowed to be taken out of the quarantine area, the requirement for written informed consent was waived by the Ethics Committee of West China Hospital and informed consent was obtained verbally (Y.M) from all participants.

\section{Consent for publication}

Not applicable.

\section{Competing interests}

The authors declare that they have no competing interests.

\section{Author details}

'Department of Geriatrics and National Clinical Research Center for Geriatrics, West China Hospital, Sichuan University, Chengdu, Sichuan Province, China. ${ }^{2}$ COVID-19 Medical Assistance Teams (Hubei) of West China Hospital, Sichuan 
University, Chengdu, Sichuan Province, China. ${ }^{3}$ Department of Critical Care Medicine, West China Hospital, Sichuan University, Chengdu, Sichuan Province, China. ${ }^{4}$ Department of Endocrinology and Metabolism, West China Hospital, Sichuan University, Chengdu, Sichuan Province, China. ${ }^{5}$ Department of Obstetrics and Gynecology, Renmin Hospital of Wuhan University, Wuhan, Hubei Province, China. ${ }^{6}$ Department of Otolaryngology-Head and Neck Surgery, Renmin Hospital of Wuhan University, Wuhan, Hubei Province, China. ${ }^{7}$ Global Health Research Center, Duke Kunshan University, Suzhou, Jiangsu Province, China.

\section{Received: 3 March 2021 Accepted: 25 May 2021} Published online: 10 June 2021

\section{References}

1. Wu ZM, McGoogan JM. Characteristics of and important lessons from the coronavirus disease 2019 (COVID-19) outbreak in China: summary of a report of 72314 cases from the Chinese Center for Disease Control and Prevention. Jama. 2020;323(13):1239-42. https://doi.org/10.1001/jama.2020.2 648.

2. Guan WJ, Ni ZY, Hu Y, Liang WH, Ou CQ, He JX, et al. Clinical characteristics of coronavirus disease 2019 in China. N Engl J Med. 2020;382(18):1708-20. https://doi.org/10.1056/NEJMoa2002032.

3. WHO Coronavirus (COVID-19) Dashboard. [https://covid19.who.int/].

4. Wang W, Tang J, Wei F. Updated understanding of the outbreak of 2019 novel coronavirus (2019-nCoV) in Wuhan, China. J Med Virol. 2020;92(4): 441-7. https://doi.org/10.1002/jmv.25689.

5. Wu P, Hao X, Lau EHY, Wong JY, Leung KSM, Wu JT, et al. Real-time tentative assessment of the epidemiological characteristics of novel coronavirus infections in Wuhan, China, as at 22 January 2020. Euro Surveill. 2020;25(3):2000044.

6. Wilson NKA, Barnard LT, Baker M. Estimating the Case Fatality Risk of COVID19 using Cases from Outside China. medRxiv preprint. https://doi.org/10.11 01/2020.02.15.20023499.

7. Li X, Xu S, Yu M, Wang K, Tao Y, Zhou Y, et al. Risk factors for severity and mortality in adult COVID-19 inpatients in Wuhan. J Allergy Clin Immunol. 2020;146(1):110-8. https://doi.org/10.1016/j.jaci.2020.04.006.

8. Zhou F, Yu T, Du R, Fan G, Liu Y, Liu Z, et al. Clinical course and risk factors for mortality of adult inpatients with COVID-19 in Wuhan, China: a retrospective cohort study. Lancet. 2020;395(10229):1054-62. https://doi. org/10.1016/S0140-6736(20)30566-3.

9. Jordan RE, Adab P, Cheng KK. Covid-19: risk factors for severe disease and death. Bmj. 2020;368:m1198.

10. Epidemiology Working Group for NCIP Epidemic Response CCfDCaP. The epidemiological characteristics of an outbreak of 2019 novel coronavirus diseases (COVID-19) in China (in chinese). Chin J Epidemiol. 2020;41(2):145-51.

11. Severe Outcomes Among Patients with Coronavirus Disease 2019 (COVID19)_United States, February 12-March 16, 2020. [https://www.cdc.gov/ mmwr/volumes/69/wr/mm6912e2.htm?s_cid=mm6912e2_w].

12. World Health Organization, Europe (April 2, 2020).Statement - Older people are at highest risk from COVID-19, but all must act to prevent community spread. http://www.euro.who.int/en/health-topics/health-emergencies/ coronavirus-covid-19/statements/statement-older-people-are-at-highest-riskfromcovid-19,-but-all-mustact-to-prevent-community-spread.

13. Epidemiologic and methodologic problems in determining nutritional status of older persons. Proceedings of a conference. Albuquerque, New Mexico, October 19-21, 1988, Am. J Clin Nutr. 1989;50(5 Suppl):1121-235.

14. Fried LP, Tangen CM, Walston J, Newman AB, Hirsch C, Gottdiener J, et al. Frailty in older adults: evidence for a phenotype. J Gerontol A Biol Sci Med Sci. 2001;56(3):M146-56. https://doi.org/10.1093/gerona/56.3.M146.

15. Castillo EM, Goodman-Gruen D, Kritz-Silverstein D, Morton DJ, Wingard DL, Barrett-Connor E. Sarcopenia in elderly men and women: the rancho Bernardo study. Am J Prev Med. 2003;25(3):226-31. https://doi.org/10.1016/ S0749-3797(03)00197-1.

16. Janssen I. Influence of sarcopenia on the development of physical disability: the cardiovascular health study. J Am Geriatr Soc. 2006;54(1):56-62. https:// doi.org/10.1111/j.1532-5415.2005.00540.x.

17. Lauretani F, Russo CR, Bandinelli S, Bartali B, Cavazzini C, Di lorio A, et al. Age-associated changes in skeletal muscles and their effect on mobility: an operational diagnosis of sarcopenia. J Appl Physiol (1985). 2003;95(5):1851-60
18. Zeng $Y, H u X$, Xie L, Han Z, Zuo Y, Yang M. The prevalence of sarcopenia in Chinese elderly nursing home residents: a comparison of 4 diagnostic criteria. J Am Med Dir Assoc. 2018;19(8):690-5. https://doi.org/10.1016/j.ja mda.2018.04.015.

19. Hsu CS, Kao JH. Sarcopenia and chronic liver diseases. Expert Rev Gastroenterol Hepatol. 2018;12(12):1229-44. https://doi.org/10.1080/174 74124.2018 .1534586

20. Ma Y, Hou L, Yang X, Huang Z, Yang $X$, Zhao N, et al. The association between frailty and severe disease among COVID-19 patients aged over 60 years in China: a prospective cohort study. BMC Med. 2020;18(1):274. https://doi.org/10.1186/s12916-020-01761-0.

21. Hewitt J, Carter B, Vilches-Moraga A, Quinn TJ, Braude P, Verduri A, et al. The effect of frailty on survival in patients with COVID-19 (COPE): a multicentre, European, observational cohort study. Lancet Public Health. 2020;5(8):e44451. https://doi.org/10.1016/\$2468-2667(20)30146-8.

22. Bollheimer LC, Buettner R, Pongratz G, Brunner-Ploss R, Hechtl C, Banas M, et al. Sarcopenia in the aging high-fat fed rat: a pilot study for modeling sarcopenic obesity in rodents. Biogerontology. 2012;13(6):609-20. https:// doi.org/10.1007/s10522-012-9405-4.

23. Cruz-Jentoft AJ, Baeyens JP, Bauer JM, Boirie Y, Cederholm T, Landi F, et al. Sarcopenia: European consensus on definition and diagnosis: report of the European working group on sarcopenia in older people. Age Ageing. 2010; 39(4):412-23. https://doi.org/10.1093/ageing/afq034.

24. Malmstrom TK, Miller DK, Simonsick EM, Ferrucci L, Morley JE. SARC-F: a symptom score to predict persons with sarcopenia at risk for poor functional outcomes. J Cachexia Sarcopenia Muscle. 2016;7(1):28-36. https:// doi.org/10.1002/jcsm.12048.

25. Organization $\mathrm{WH}$ : Clinical management of severe acute respiratory infection when novel coronavirus (nCoV) infection is suspected: interim guidance. 2020.

26. China NHCotPsRo: Diagnosis and treatment protocol for novel coronavirus infection-induced pneumonia version 7 (trial). 2020.

27. Organization $\mathrm{WH}$. WHO Clinical management of severe acute respiratory infection (SARI) when COVID-19 disease is suspected; 2019. p. 12.

28. ARDS Definition Task Force R, V. M, Rubenfeld GD, Thompson BT, Ferguson $N D$, Caldwell E, Fan $E$, et al. Acute respiratory distress syndrome: the Berlin Definition. Jama. 2012;307(23):2526-33.

29. Sheean PM, Peterson SJ, Gomez Perez S, Troy KL, Patel A, Sclamberg JS, et al. The prevalence of sarcopenia in patients with respiratory failure classified as normally nourished using computed tomography and subjective global assessment. JPEN J Parenter Enteral Nutr. 2014;38(7):873-9. https://doi.org/10.1177/0148607113500308.

30. Yardimci B, Aksoy SM, Ozkaya I, Demir T, Tezcan G, Kaptanoglu AY. Anthropometric measurements may be informative for nursing homeacquired pneumonia. Pak J Med Sci. 2016;32(3):694-9. https://doi.org/10.12 669/pjms.323.9635.

31. Altuna-Venegas S, Aliaga-Vega R, Maguiña JL, Parodi JF, Runzer-Colmenares FM. Risk of community-acquired pneumonia in older adults with sarcopenia of a hospital from Callao, Peru 2010-2015. Arch Gerontol Geriatr. 2019;82: 100-5. https://doi.org/10.1016/j.archger.2019.01.008.

32. Maeda K, Akagi J. Muscle mass loss is a potential predictor of 90-day mortality in older adults with aspiration pneumonia. J Am Geriatr Soc. 2017; 65(1):e18-22. https://doi.org/10.1111/jgs.14543.

33. Wakabayashi H, Sakuma K. Rehabilitation nutrition for sarcopenia with disability: a combination of both rehabilitation and nutrition care management. J Cachexia Sarcopenia Muscle. 2014;5(4):269-77. https://doi. org/10.1007/s13539-014-0162-x.

34. Maeda K, Akagi J. Sarcopenia is an independent risk factor of dysphagia in hospitalized older people. Geriatr Gerontol Int. 2016;16(4):515-21. https:// doi.org/10.1111/ggi.12486.

35. Wakabayashi H. Presbyphagia and Sarcopenic dysphagia: association between aging, sarcopenia, and deglutition disorders. J Frailty Aging. 2014; 3(2):97-103. https://doi.org/10.14283/jfa.2014.8.

36. Zheng Z, Peng F, Xu B, Zhao J, Liu H, Peng J, et al. Risk factors of critical \& mortal COVID-19 cases: a systematic literature review and meta-analysis. J Inf Secur. 2020;81(2):e16-25.

37. Liu K, Chen Y, Lin R, Han K. Clinical features of COVID-19 in elderly patients: a comparison with young and middle-aged patients. J Inf Secur. 2020;80(6): e14-8.

38. Can B, Kara O, Kizilarslanoglu MC, Arik G, Aycicek GS, Sumer F, et al. Serum markers of inflammation and oxidative stress in sarcopenia. Aging Clin Exp Res. 2017;29(4):745-52. https://doi.org/10.1007/s40520-016-0626-2. 
39. Livshits $\mathrm{G}$, Kalinkovich A. Inflammaging as a common ground for the development and maintenance of sarcopenia, obesity, cardiomyopathy and dysbiosis. Ageing Res Rev. 2019;56:100980. https://doi.org/10.1016/j.arr.201 9.100980 .

40. Bano G, Trevisan C, Carraro S, Solmi M, Luchini C, Stubbs B, et al. Inflammation and sarcopenia: a systematic review and meta-analysis. Maturitas. 2017;96:10-5. https://doi.org/10.1016/j.maturitas.2016.11.006.

41. Nikolich-Zugich J, Knox KS, Rios CT, Natt B, Bhattacharya D, Fain MJ. SARSCoV-2 and COVID-19 in older adults: what we may expect regarding pathogenesis, immune responses, and outcomes. Geroscience. 2020;42(2): 505-14. https://doi.org/10.1007/s11357-020-00186-0.

42. Kadkhoda K. COVID-19: an Immunopathological View. mSphere. 2020;5(2): e00344-20.

43. Constantin D, Menon MK, Houchen-Wolloff L, Morgan MD, Singh SJ, Greenhaff $\mathrm{P}$, et al. Skeletal muscle molecular responses to resistance training and dietary supplementation in COPD. Thorax. 2013;68(7):625-33. https:// doi.org/10.1136/thoraxjnl-2012-202764.

44. Nelke C, Dziewas R, Minnerup J, Meuth SG, Ruck T. Skeletal muscle as potential central link between sarcopenia and immune senescence. EBioMedicine. 2019;49:381-8. https://doi.org/10.1016/j.ebiom.2019.10.034.

45. McGonagle D, Sharif K, O'Regan A, Bridgewood C. The role of cytokines including Interleukin-6 in COVID-19 induced pneumonia and macrophage activation syndrome-like disease. Autoimmun Rev. 2020;19(6):102537. https://doi.org/10.1016/j.autrev.2020.102537.

46. Liu B, Li M, Zhou Z, Guan X, Xiang Y. Can we use interleukin-6 (IL-6) blockade for coronavirus disease 2019 (COVID-19)-induced cytokine release syndrome (CRS)? J Autoimmun. 2020;111:102452. https://doi.org/10.1016/j.ja ut.2020.102452.

47. Dalle S, Rossmeislova L, Koppo K. The role of inflammation in age-related sarcopenia. Front Physiol. 2017;8:1045. https://doi.org/10.3389/fphys.2017.01 045.

48. Alemán H, Esparza J, Ramirez FA, Astiazaran H, Payette H. Longitudinal evidence on the association between interleukin- 6 and C-reactive protein with the loss of total appendicular skeletal muscle in free-living older men and women. Age Ageing. 2011;40(4):469-75. https://doi.org/10.1093/a geing/afr040.

49. Zhang C, Wu Z, Li JW, Zhao H, Wang GQ. Cytokine release syndrome in severe COVID-19: interleukin-6 receptor antagonist tocilizumab may be the key to reduce mortality. Int J Antimicrob Agents. 2020;55(5):105954. https:// doi.org/10.1016/j.jjantimicag.2020.105954.

50. Pedersen SF, Ho YC. SARS-CoV-2: a storm is raging. J Clin Invest. 2020;130(5): 2202-5. https://doi.org/10.1172/JCl137647

51. Ida S, Nakai M, Ito S, Ishihara Y, Imataka K, Uchida A, et al. Association Between Sarcopenia and Mild Cognitive Impairment Using the Japanese Version of the SARC-F in Elderly Patients With Diabetes. J Am Med Dir Assoc. 2017;18(9):809.e809-13.

52. Ida S, Murata K, Nakadachi D, Ishihara Y, Imataka K, Uchida A, et al. Development of a Japanese version of the SARC-F for diabetic patients: an examination of reliability and validity. Aging Clin Exp Res. 2017;29(5):935-42. https://doi.org/10.1007/s40520-016-0668-5.

53. Parra-Rodríguez L, Szlejf C, García-González Al, Malmstrom TK, Cruz-Arenas E, Rosas-Carrasco O. Cross-cultural adaptation and validation of the Spanishlanguage version of the SARC-F to assess sarcopenia in Mexican community-dwelling older adults. J Am Med Dir Assoc. 2016;17(12):1142-6. https://doi.org/10.1016/j.jamda.2016.09.008.

\section{Publisher's Note}

Springer Nature remains neutral with regard to jurisdictional claims in published maps and institutional affiliations.

Ready to submit your research? Choose BMC and benefit from:

- fast, convenient online submission

- thorough peer review by experienced researchers in your field

- rapid publication on acceptance

- support for research data, including large and complex data types

- gold Open Access which fosters wider collaboration and increased citations

- maximum visibility for your research: over $100 \mathrm{M}$ website views per year

At BMC, research is always in progress.

Learn more biomedcentral.com/submissions 